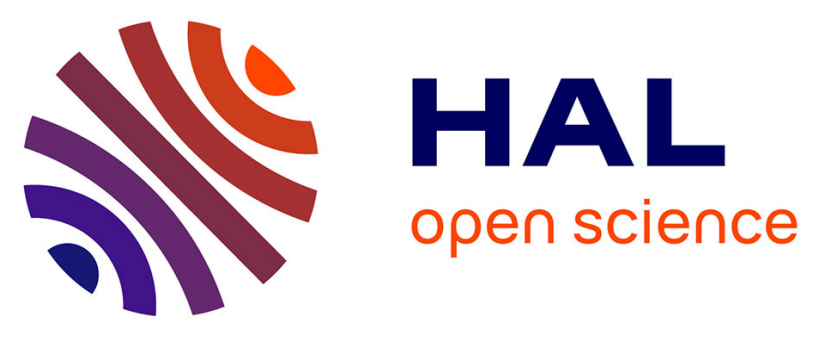

\title{
Vaccination against influenza and pneumococcal infections in patients with autoimmune disorders under biological therapy: Coverage and attitudes in patients and physicians
}

\author{
Hajer Lejri-El Euchi, Emmanuel Chirpaz, Aurélie Foucher, Nathalie \\ Sultan-Bichat, Andry Randrianjohany, Patrice Poubeau, Etienne Gamon, \\ Céline Roussin, Sophie Osdoit, Loïc Raffray
}

\section{- To cite this version:}

Hajer Lejri-El Euchi, Emmanuel Chirpaz, Aurélie Foucher, Nathalie Sultan-Bichat, Andry Randrianjohany, et al.. Vaccination against influenza and pneumococcal infections in patients with autoimmune disorders under biological therapy: Coverage and attitudes in patients and physicians. European Journal of Internal Medicine, 2019, 69, pp.25 - 31. 10.1016/j.ejim.2019.08.010 . hal-03488896

\section{HAL Id: hal-03488896 https://hal.science/hal-03488896}

Submitted on 21 Dec 2021

HAL is a multi-disciplinary open access archive for the deposit and dissemination of scientific research documents, whether they are published or not. The documents may come from teaching and research institutions in France or abroad, or from public or private research centers.
L'archive ouverte pluridisciplinaire HAL, est destinée au dépôt et à la diffusion de documents scientifiques de niveau recherche, publiés ou non, émanant des établissements d'enseignement et de recherche français ou étrangers, des laboratoires publics ou privés.

\section{(ㅇ)(1) $\$$}

Distributed under a Creative Commons Attribution - NonCommerciall 4.0 International 


\section{Title Page}

Title:

Vaccination against influenza and pneumococcal infections in patients with autoimmune disorders under biological therapy: coverage and attitudes in patients and physicians.

\section{Authors:}

Hajer Lejri-El Euchi ${ }^{\mathrm{a}}$, Emmanuel Chirpaz ${ }^{\mathrm{b}}$, Aurélie Foucher ${ }^{\mathrm{c}}$, Nathalie Sultan-Bichat ${ }^{\mathrm{d}}$, Andry Randrianjohany ${ }^{\mathrm{e}}$, Patrice Poubeau ${ }^{\mathrm{c}}$, Etienne Gamon ${ }^{\mathrm{f}}$, Céline Roussin $^{\mathrm{d}}$, Sophie Osdoit ${ }^{\mathrm{a}}$, Loïc Raffray ${ }^{\mathrm{a}}$

\section{Affiliations:}

${ }^{a}$ Internal Medicine and Dermatology Unit, Reunion University Hospital, Saint Denis, Reunion Island, France,

${ }^{b}$ Statistics and methodological Unit, INSERM CIC 1410, Reunion University Hospital, Saint Denis, Reunion Island, France,

${ }^{c}$ Internal Medicine Unit, Reunion University Hospital, Saint Pierre, Reunion Island, France,

${ }^{\mathrm{d}}$ Internal Medicine and Dermatology Unit, Gabriel Martin Hospital, Saint Paul, Reunion Island, France,

${ }^{\mathrm{e}}$ Internal Medicine Unit, GHER Hospital, Saint Benoit, Reunion Island, France

${ }^{f}$ Rheumatology Unit, Reunion University Hospital, Saint Denis, Reunion Island, France, 
Corresponding author: Loïc Raffray

loic.raffray@chu-reunion.fr

phone: +262 262905450

fax: +262 262906451

Internal Medicine and Dermatology Unit, Reunion University Hospital, Allee des Topazes,

97405 CS Saint Denis, Reunion Island, France

\section{Authors' emails:}

hajer.eleuchi@gmail.com

emmanuel.chirpaz@chu-reunion.fr

aurelie.foucher@chu-reunion.fr

sultanbichat.n@ch-gmartin.fr

etiennegamon@gmail.com

a.randrianjohany@gher.fr

roussin.c@ch-gmartin.fr

sophie.osdoit@chu-reunion.fr

patrice.poubeau@chu-reunion.fr

loic.raffray@chu-reunion.fr 


\begin{abstract}

\section{Background:}

Patients under biological therapy for auto-immune disease are considered immunosuppressed and several recent recommendations highlight the need for vaccination against influenza and pneumococcal infections. The aims of this study were to evaluate influenza and pneumococcal vaccine coverage among patients receiving biological therapy and identify factors associated with vaccine uptake within this population.
\end{abstract}

\title{
Methods:
}

A retrospective cross-sectional study was performed in adult patients attending hospitals for an auto-immune/inflammatory disease and treated with biological therapy. Vaccine uptake was evidenced from patient's medical records or from their pharmacist's records.

Questionnaires about attitudes and knowledge regarding vaccinations were administered to patients and their physicians. Multivariable logistic regression was used to determine factors significantly associated with influenza and pneumococcal vaccine receipt.

\section{Results:}

A total of 208 patients were included: $52 \%$ female and mean age 50.6 ( \pm 14.7$)$ years. Among them 173 completed the questionnaire while 72 physicians replied. Underlying inflammatory diseases were rheumatisms (46\%), bowel diseases (31\%) and skin diseases (23\%). Vaccine uptake was $28 \%$ for influenza, $48 \%$ for pneumococcus and $22 \%$ received both vaccines. Main factors associated to positive uptake were receiving a prescription from a physician, as well as having a good knowledge of vaccines. Factors limiting vaccination were a negative attitude toward vaccines in general, and belonging to the group of inflammatory bowel diseases. 


\section{Conclusions:}

Vaccine coverage for influenza and pneumococcal infections are low in the patients under biologics for auto-immune/inflammatory disease. Health policies should reinforce information and promotion of these vaccines among these patients but also the prescribers.

\section{Keywords:}

Vaccination; influenza, pneumococcal infections, biological therapy, immunocompromised host, knowledge 


\section{Main body}

\section{Introduction}

Biological therapies are increasingly employed to treat autoimmune diseases as they offer targeted-therapy, but are nevertheless associated with more frequent infections and related mortality $[1,2]$. Among the commonest infections in immunocompromised patients are influenza and pneumococcal infections [3], despite the availability of safe and effective vaccines [4-8]. These vaccines are recommended for immunocompromised individuals by several public health policies or academic societies [9]. For instance, French authorities recommend a yearly uptake for influenza, and for pneumococcus the administration of the 13-valent conjugate vaccine (PCV13) followed 2 months after by the 23 -valent polysaccharide vaccine (PPSV23) [10]. Although flu and pneumococcal vaccination were previously recommended during the use of corticosteroids or immunosuppressants, biologics have been acknowledged as an additional indication only lately [9].

Limited data are available on vaccine coverage since the recommendations have been updated and notably on vaccine uptake in biologics immuno-suppressed patients. Globally, the coverage for seasonal flu and pneumococcal vaccines appears low, with rates ranging from $30 \%$ to $65 \%$ [11-16]. Studies in the field were usually centered on a specific disease, but a large audit recruiting 2881 patients from various autoimmune disease groups indicated that being treated with biologics was negatively associated with vaccine uptake [16]. Absence of vaccination was related to the patients' lack of information and/or prescription, negative attitude toward vaccines in general and the fear of side effects $[11,12,16]$. A better 
knowledge of major hurdles to vaccine uptake is important to adapt public health policies and improve vaccine coverage.

The main goal of our study was to assess the vaccine uptake (influenza and pneumococcal) in patients with various autoimmune diseases treated with biologics. We also aimed at exploring the attitudes and knowledge of the patients and their physicians, to identify factors associated with the decision to administer these vaccines.

\section{Patients and methods}

\subsection{Objectives and population selection}

The main objective of the study was to evaluate seasonal flu and pneumococcal vaccine coverage in patients with autoimmune/inflammatory disease receiving biologic therapy. Secondary objective was to assess association between vaccine uptake and vaccine perception/knowledge. We performed a multicentre cross-sectional survey in the 4 public hospitals of the French oversea territory of La Reunion island, located in the South West of Indian Ocean (hospitals: centre hospitalier Félix Guyon, groupe hospitalier Sud Réunion, centre hospitalier Gabriel Martin and groupe hospitalier Est Réunion). We recruited consecutive patients with autoimmune/inflammatory disorders treated with biologics. Patients were identified during their passage at hospital for their disease as outpatients or during day hospitalisation. Patients screening was also completed with hospital informatics database. Patients were enrolled by their specialist in charge. Inclusion criteria were an age $\geq 18$ years, being affiliated to national health insurance (therefore having vaccines for free) and having an autoimmune/inflammatory disease with an ongoing biological therapy 
between April and September 2015. These dates were chosen accordingly to the flu epidemic period and related vaccination campaign in La Reunion and South hemisphere. An exclusion criterion was the refusal of the patient to participate.

\subsection{Data collection and intervention}

The following data were collected between December 2015 and August 2016 in medical files from hospital and from patients' general practitioner records: demographics, medical history, type of autoimmune/inflammatory disease and related treatments including immunosuppressive therapy and past/current biological therapies, vaccination status for influenza during 2015 epidemic season and pneumococcal vaccine uptake in the 5 previous years. Other risk factors for seasonal influenza vaccine uptake were listed, which at the time of the study were defined as follow by the 2014 French Health authority recommendations: age $\geq 65$, chronic lung disease, chronic cardiac failure, chronic kidney failure, chronic liver disease, immune deficiency, morbid obesity, diabetes, pregnancy [10]. The following comorbidities were recognized as risk factors for pneumococcal vaccine uptake by the French Health Authorities in 2014: asplenia, immune deficiency, chronic lung disease, chronic cardiac disease, chronic kidney failure, chronic liver disease, diabetes, skull base defect with cerebrospinal fluid leaks [10].

Patients were considered vaccinated (primary endpoint) if they had one of the following: patient's personal immunization record evidencing effective uptake (sticker with batch number), medical record indicating vaccination was done, vaccine prescription recorded in the notes and usual pharmacy indicating vaccine was delivered to the patient. For pneumococcal vaccination, the vaccination was considered complete if the patient had 
received the PCV13 vaccine and the vaccine PPSV23 vaccine. The vaccination was considered incomplete if he had received only one of the two vaccines.

A paper-based questionnaire was proposed to all included patients and their referring physician (specialist and general practitioner). The patient's questionnaire requested details about awareness of their vaccination status for the seasonal flu vaccine during the last year and for the pneumococcal vaccine in the past years. It also asked questions on vaccination perception and knowledge with a multiple response choice on a 5-point Likert scale. The patient could refuse without giving any specific reason. The practitioner's questionnaire requested details on their knowledge about vaccination recommendations in immunosuppressed patients and about their habits for seasonal flu and pneumococcal vaccines prescription, as well as their attitude toward vaccines in general. Physicians were solicited at least twice through phone calls or emails.

\subsection{Ethics}

Informed consent was provided prior to enrolment and data were collected anonymously. The study was conducted according to the principles expressed in the Declaration of Helsinki and approved by the human ethic committee CPP Ile De France VI (ref A02198-45).

\subsection{Statistical analysis}

Qualitative variables were expressed as percentages, quantitative variables as means and standard deviation (SD). Normality of the data was assessed using the Shapiro-Wilk test and homoscedasticity using the Levene's test. Comparisons of percentages were performed 
with the Chi2 test or the Fisher's exact test, as appropriate. Comparison analyses of continuous variables were performed with Student t-test or Mann-Whitney's test. Flu and pneumococcal vaccine uptake determinants were studied separately, by bivariate analysis. To assess independent determinants of vaccine uptake, multivariate analyses by logistic regression were performed. Variables with a $p$-value $<0.2$ at the bivariate analysis were included in the models, and selected by backward stepwise selection procedure (removal criteria: $p>0.1$. Age and gender were forced in the models. All hypotheses were tested with a two-tailed alpha value of 5\%. Results are expressed with odds ratio (OR) and 95\% confidence interval $(\mathrm{Cl})$ with the corresponding $\mathrm{p}$-value. All analyses were performed using STATA 11.2 (StataCorp, Texas).

\section{Results}

\subsection{Study population}

A total of 208 patients were included in the study. Main characteristics are described in table 1. Underlying diseases corresponded to 3 main groups: joint, bowel and skin inflammatory diseases. Patients were treated by the ongoing biological therapy for 3.9 ( \pm 2.9) years in average. If not considering the use of biologics, many patients had additional risk factors considered as indications for vaccine uptake: 64 (30.8\%) and 46 (22.1\%) patients for influenza and pneumococcal infections respectively. 


\subsection{Vaccination attitudes and knowledge}

Attitudes and knowledge about vaccination were explored through questionnaires administered to patients and their physicians in charge.

\subsubsection{For physicians}

The questionnaire was completed by 72 physicians (33\% responders): 49 were general practitioners and 23 were specialists. A large majority of physicians had a positive attitude toward vaccine: $65 \%$ were clearly favorable, $18 \%$ rather favorable, and $17 \%$ declared that it depends on the vaccine. More than $70 \%$ stated being aware of the most recent recommendations and stated prescribing the influenza vaccine for patients under biologics. For pneumococcal vaccine, only $59 \%$ of general practitioners declared prescribing the vaccine against $83 \%$ of specialists in charge $(p=0.049)$. The main reason for not doing so was the fact of forgetting for most physicians. In addition, many general practitioners considered that this prescription should be supervised by the specialist only. However, the vast majority of physicians (83\%) considered that vaccination responsibility was to be shared between general practitioners and specialists. Rarely physicians declared not prescribing the vaccines because they feared a side-effect, or because they estimated the vaccine was useless. Of note, $61 \%$ of the physicians declared having insufficient information about vaccination in the field of immunosuppressant therapy, $86 \%$ being general practitioners.

\subsubsection{For patients}

Among the 208 patients included, 173 (83\%) completed the questionnaire. Attitudes toward vaccines in general were contrasted: $19 \%$ with favorable opinions, $30 \%$ rather 
favorable, $12 \%$ not favorable, $32 \%$ mixed feelings depending on the vaccine, and $9 \%$ without opinion. Regarding general knowledge about vaccination, patients self-estimated their knowledge as: high for $11 \%$, average for $44 \%$, low for $24 \%$ and restricted for $21 \%$.

Interestingly, $65 \%$ of the patients considered not being appropriately informed about vaccines and that such information should be delivered by the physicians, mainly primarycare physician. Regarding knowledge about influenza vaccine for their specific case, $47 \%$ estimated that this vaccine was useful, $27 \%$ not useful and others had no opinion. The main fears related to vaccination were the risk of an auto-immune disease flare, an allergic reaction and the development of a genuine infection following the jab.

\subsection{Vaccine coverage and correlates}

\subsubsection{Vaccine uptake}

Results for vaccine coverage are presented in figure 1 . Main results are a coverage rate of $28 \%$ for influenza and $49 \%$ for pneumococcal infections. For pneumococcal vaccine, vaccination was complete in $42 \%$ of the patients while $7 \%$ received only one of the 2 vaccines. The vaccination rates varied according to the underlying disease. The lowest rates were registered for bowel disease group ( $9 \%$ for influenza and $28 \%$ for pneumococcal infections) and the highest rates for joint disease group (38\% and 61\% respectively). Interestingly, results from the objective method and the self-declaration assessment, as part of the administered questionnaire, yielded different vaccine uptake rates. The concordance was of $88 \%$ for influenza vaccine and of $44 \%(77 / 175)$ for pneumococcal vaccine uptake. 


\subsubsection{Factors associated with vaccination}

Table 2 and table 3 report the factors associated to vaccine uptake for influenza and pneumococcal vaccine respectively. Analysis was performed on the 173 patients for whom no data was missing, including answers to questionnaire.

In the bivariate analysis, age was significantly associated to vaccine uptake only for influenza: $\mathrm{OR}=3.4(\mathrm{Cl}: 1.23-9.43, \mathrm{P}=0.02)$ and $5.28(\mathrm{Cl}: 1.6-17.83, \mathrm{P}=0.02)$ for people aged 40-64 years and people over 65 years respectively compared to those under 40 years. Sex and age were not statistically associated to vaccine uptake in the multivariate analysis. Being in the group of inflammatory bowel diseases was negatively associated with both vaccinations. Unfavorable attitude toward vaccines in general was negatively associated to influenza vaccine uptake (adjusted OR 0.04 with $95 \% \mathrm{Cl} 0.003-0.46$ ), but not to pneumococcal vaccine. The following factors were positively associated with vaccination: level of general knowledge about vaccines, receiving a prescription from physicians in charge or a reminder/recall letter from health authorities. Patients who received the flu vaccine in previous years were more likely to be vaccinated for the study period. Some factors were statistically associated to vaccine uptake in the bivariate analysis but not selected through the backward selection process of multivariate analysis: the fact of being advised for these vaccines, having another risk factor for severe flu disease and being under immunosuppressant in addition to biological therapy for the pneumococcal vaccine. 


\section{Discussion}

Our study shows a poor vaccine coverage for influenza and pneumococcal infections in a cohort of patients receiving biological therapy for autoimmune/inflammatory disorders. Vaccination uptake was negatively associated with unfavorable attitude toward vaccines, and the fact of belonging to the group of inflammatory bowel disease. Factors positively associated with vaccine uptake were a good knowledge about vaccines and the fact of receiving a prescription for the vaccination from the physicians in charge or receiving a reminder from health authorities.

La Reunion is a French territory with a population characterized by admixture between descents from Africa, Europe and Asia. Average income and education levels are lower than in France mainland and Europe in general. However, people benefit from the French national health insurance system and therefore vaccines are freely available for people with chronic autoimmune diseases. Hence finance is not a limitation to vaccination but education may constitute a limitation. In 2015, the estimate from Reunion health agency was a vaccine coverage of $34 \%$ for influenza for the 110,000 at-risk individuals among 850,000 inhabitants [17]. On the same period, it is estimated that nearly 180,000 individuals suffered from seasonal flu [17].

The vaccination rates found in our study were of $28 \%$ for influenza and $48 \%$ for pneumococcal vaccine. The low coverage evidenced in our study is in line with several studies conducted in immunocompromised patients, with average rates ranging from $30 \%$ to $65 \%$ for influenza and pneumococcal vaccines [11-16,18,19], although the pneumococcal vaccine uptake is usually lower in these published data, unlike our studied population. Some observations suggested that immunosuppressant and/or biologics use was an under- 
recognized risk factor requiring immunization, and that this group had therefore a lower vaccine coverage $[16,20,21]$. Our study included only patients under biologics thus did not allow comparison with other groups of treatment-related immune suppression. However, we observed a moderately better coverage for both vaccines when patients had at least one other risk factor indicating a need for vaccination, suggesting biologics use may be an overlooked risk factor here. In the same line, the rate for seasonal flu vaccination in our biologic-treated patients is also lower than the estimate for the whole eligible population of Reunion island: 28 vs 34\% [17]. The hypothesis that biologics are an under-recognized risk factor is not sustained by studies where it was associated to a better vaccine uptake $[18,19]$. In a large-scale European epidemiological study it was estimated that only $44 \%$ of eligible individuals received annual influenza vaccination [22]. Thus, coverage rates for influenza vaccine retrieved in immunosuppressed $[11-16,18,19]$, including those under biologics, are somehow similar to other groups at risk evaluated in the latter study [22]. Overall, the rates found in our study and other similar studies argue for insufficient coverage and the need to understand this phenomenon.

Crucial information obtained from our questionnaires and multivariate analysis is the importance of knowledge of vaccines and advice/prescription from health professionals to promote vaccination. Previous studies have already underpinned information/prescription about vaccines as key elements to achieve a better vaccine coverage in patients with [16] $[13,14,20]$ or without immunocompromised condition [23-25]. Moreover, patients are usually in demand for more information about vaccines from their practitioners and the healthcare providers [26]. In our study, patients who estimated having a good knowledge about vaccines were more likely to be vaccinated. Therefore, information about vaccines should be routinely and repeatedly delivered in the population of drug-induced 
immunocompromised. The patients of the present study acknowledged that this information should be delivered by their primary care physician in priority. In Reunion (and France) largescale information campaign through media are already performed for influenza vaccination in the elderly. This model should be extended to other population at risk.

Lack of awareness regarding infection risk related to biologics is probably shared by patients and physicians. From the point of view of clinicians, this may be explained by the absence of specific studies conducted in immunosuppressed individuals demonstrating a clear benefit of vaccination in terms of mortality and/or morbidity. As a result, the relevance of these vaccinations in immunocompromised patients is often questioned. A recent metaanalysis showed that pneumococcal infections incidence was 6-times higher in patients with inflammatory diseases compared to healthy controls [3]. Influenza is also more frequent and associated to more complications in chronic inflammatory diseases $[27,28]$. Alleged vaccine efficacy in the immunosuppressed population relies on evidenced immunogenicity, but not on survival rates. However, positive impact on survival with influenza vaccine and decrease in pneumonia rates with pneumococcal vaccine have been shown in larger populations at risk, the elderly for example [29-31]. Therefore, usefulness and efficacy of these vaccines can probably be generalized to immunocompromised individuals from inflammatory disease group.

Although most of the physicians in our study declared comply with the most recent recommendations, there were still many patients stating they were not offered to be vaccinated. Several explanations may be hypothesized to explain this low prescription: a lack of medical awareness of vaccination utility and/or recommendations, the fact of forgetting to prescribe the vaccines, and the feeling that this prescription should be supervised by the specialist from the point of view of GP. In our study many practitioners estimated their 
knowledge about vaccination was insufficient and implicitly would benefit from dedicated training. As an illustration, the fact that patients in the group of inflammatory bowel disease were less vaccinated suggests that some physicians are less aware of vaccination needs. These observations are backed up by the comparison of two studies performed by the same authors and with the same methods demonstrating a lower coverage in inflammatory bowel disease patients (34\% for influenza, 38\% for pneumococcal infections) compared to a larger group of autoimmune diseases (57\% for influenza, $51 \%$ pneumococcal vaccines) $[14,16]$. This strengthens the conviction that physicians' information plays a critical role in improving vaccination rate. Another factor limiting vaccine proposal is the problem of oversight. This negligence was stated as the most important by the physicians of our study, but also in other studies $[13,21]$. One solution to avoid this pitfall is a systematic and periodic assessment of risk factors and immunization status, associated to physician and patient reminder/recall strategies [32,33]. In order to optimise these reminder strategies, health professionals could maybe use the new technologies, such as recall messages or educative videos delivered through smartphones, public health campaign posted on social networks. The field of connected health is increasingly developing and benefits from the demand of patients who are calling for original and modern ways to deliver information. Health professionals could also benefit from new technologies and digital records that deliver appropriate automatic reminders to encourage vaccine prescriptions according to the patient's status. Further studies are needed to assess efficacy of these methods.

This study suffers from several limitations, one being the questionable accuracy of information retrieved from records' retrospective analysis and also from patients' declarations because of recall bias. To limit these weaknesses, we used an objective definition of vaccine uptake, with direct and indirect proof, thereby increasing accuracy of 
vaccine uptake results. Another limitation is the relatively small sample size. However, we focused on a specific group of drug-related immunocompromised patients, one of largest to date with an objective assessment of vaccine uptake. In addition, we did not limit our analysis to a specific group of inflammatory disease which allowed to make comparisons between these groups of diseases. Another strength is the collection of information regarding attitudes and knowledge from both patients and related health professionals. This raised interesting results and nuanced the interpretation of answers given to the questionnaires.

\section{Conclusion}

Vaccination coverage for influenza and pneumococcal vaccines in our group of biologics-immunosuppressed patients is rather low. This reflects insufficient implementation of national and international recommendations. Biologic therapies appear as an underrecognized risk factor requiring immunization. This concern may be partly explained by suboptimal information delivered to patients and healthcare providers. In terms of public health policy, appropriate actions should focus on improving information on vaccines indications/utility and promoting knowledge about these vaccines.

\section{Declaration of interests: none}

\section{Acknowledgments}

The authors thank the practitioners and nurses who helped in patients' recruitment, as well as data completion and survey participation. 


\section{Funding}

This research did not receive any specific grant from funding agencies in the public, commercial, or not-for-profit sectors. 


\section{References}

[1] Furst DE. The risk of infections with biologic therapies for rheumatoid arthritis. Semin Arthritis Rheum 2010;39:327-46. doi:10.1016/j.semarthrit.2008.10.002.

[2] Her M, Kavanaugh A. Alterations in immune function with biologic therapies for autoimmune disease. J Allergy Clin Immunol 2016;137:19-27. doi:10.1016/j.jaci.2015.10.023.

[3] van Aalst M, Lötsch F, Spijker R, van der Meer JTM, Langendam MW, Goorhuis A, et al. Incidence of invasive pneumococcal disease in immunocompromised patients: A systematic review and meta-analysis. Travel Med Infect Dis 2018. doi:10.1016/j.tmaid.2018.05.016.

[4] Moberley S, Holden J, Tatham DP, Andrews RM. Vaccines for preventing pneumococcal infection in adults. Cochrane Database Syst Rev 2013:CD000422. doi:10.1002/14651858.CD000422.pub3.

[5] Agarwal N, Ollington K, Kaneshiro M, Frenck R, Melmed GY. Are immunosuppressive medications associated with decreased responses to routine immunizations? A systematic review. Vaccine 2012;30:1413-24. doi:10.1016/j.vaccine.2011.11.109.

[6] Pugès M, Biscay P, Barnetche T, Truchetet M-É, Richez C, Seneschal J, et al. Immunogenicity and impact on disease activity of influenza and pneumococcal vaccines in systemic lupus erythematosus: a systematic literature review and meta-analysis. Rheumatology (Oxford) 2016;55:1664-72. doi:10.1093/rheumatology/kew211.

[7] Sangil A, Xercavins M, Rodríguez-Carballeira M, Andrés M, Riera M, Espejo E, et al. Impact of vaccination on invasive pneumococcal disease in adults with focus on the 
immunosuppressed. J Infect 2015;71:422-7. doi:10.1016/j.jinf.2015.07.004.

[8] Shigayeva A, Rudnick W, Green K, Chen DK, Demczuk W, Gold WL, et al. Invasive Pneumococcal Disease Among Immunocompromised Persons: Implications for Vaccination Programs. Clin Infect Dis 2016;62:139-47. doi:10.1093/cid/civ803.

[9] Lopez A, Mariette X, Bachelez H, Belot A, Bonnotte B, Hachulla E, et al. Vaccination recommendations for the adult immunosuppressed patient: A systematic review and comprehensive field synopsis. J Autoimmun 2017;80:10-27. doi:10.1016/j.jaut.2017.03.011.

[10] HCSP. Vaccination des personnes immunodéprimées ou aspléniques. Recommandations actualisées. Paris: Haut Conseil de la Santé Publique; 2014.

[11] Hua C, Morel J, Ardouin E, Ricard E, Foret J, Mathieu S, et al. Reasons for nonvaccination in French rheumatoid arthritis and spondyloarthritis patients. Rheumatology (Oxford) 2015;54:748-50. doi:10.1093/rheumatology/keu531.

[12] Michel M, Vincent FB, Rio S, Leon N, Marcelli C. Influenza vaccination status in rheumatoid arthritis and spondyloarthritis patients receiving biologic DMARDs. Joint Bone Spine 2016;83:237-8. doi:10.1016/j.jbspin.2015.02.016.

[13] Brocq O, Acquacalda E, Berthier F, Albert C, Bolla G, Millasseau E, et al. Influenza and pneumococcal vaccine coverage in 584 patients taking biological therapy for chronic inflammatory joint: A retrospective study. Joint Bone Spine 2016;83:155-9. doi:10.1016/j.jbspin.2015.11.005.

[14] Loubet P, Verger P, Abitbol V, Peyrin-Biroulet L, Launay O. Pneumococcal and influenza vaccine uptake in adults with inflammatory bowel disease in France: Results from a web-based study. Dig Liver Dis 2018. doi:10.1016/j.dld.2017.12.027.

[15] Bonhomme A, Fréling E, Reigneau M, Poreaux C, Valois A, Truchetet F, et al. 
[Vaccination status in psoriasis patients on immunosuppressant therapy (including biologics)]. Ann Dermatol Venereol 2017;144:92-9. doi:10.1016/j.annder.2016.09.035.

[16] Loubet $P$, Kernéis $S$, Groh $M$, Loulergue $P$, Blanche $P$, Verger $P$, et al. Attitude, knowledge and factors associated with influenza and pneumococcal vaccine uptake in a large cohort of patients with secondary immune deficiency. Vaccine 2015;33:3703-8. doi:10.1016/j.vaccine.2015.06.012.

[17] ARS Océan Indien. Seasonal flu 2015. https://www.oceanindien.ars.sante.fr/sites/default/files/2016-12/ARS_Presse_vaccination_grippe_13.04.16.pdf (accessed April 29, 2019).

[18] Hmamouchi I, Winthrop K, Launay O, Dougados M. Low rate of influenza and pneumococcal vaccine coverage in rheumatoid arthritis: data from the international COMORA cohort. Vaccine 2015;33:1446-52. doi:10.1016/j.vaccine.2015.01.065.

[19] Malhi G, Rumman A, Thanabalan R, Croitoru K, Silverberg MS, Hillary Steinhart A, et al. Vaccination in inflammatory bowel disease patients: attitudes, knowledge, and uptake. J Crohns Colitis 2015;9:439-44. doi:10.1093/ecco-jcc/jjv064.

[20] Sowden E, Mitchell WS. An audit of influenza and pneumococcal vaccination in rheumatology outpatients. BMC Musculoskelet Disord 2007;8:58. doi:10.1186/1471-24748-58.

[21] Haroon M, Adeeb F, Eltahir A, Harney S. The uptake of influenza and pneumococcal vaccination among immunocompromised patients attending rheumatology outpatient clinics. Joint Bone Spine 2011;78:374-7. doi:10.1016/j.jbspin.2010.10.012.

[22] Preaud E, Durand L, Macabeo B, Farkas N, Sloesen B, Palache A, et al. Annual public health and economic benefits of seasonal influenza vaccination: a European estimate. BMC Public Health 2014;14:813. doi:10.1186/1471-2458-14-813. 
[23] Nichol KL, Mac Donald R, Hauge M. Factors associated with influenza and pneumococcal vaccination behavior among high-risk adults. J Gen Intern Med 1996;11:6737.

[24] Schneeberg A, Bettinger JA, McNeil S, Ward BJ, Dionne M, Cooper C, et al. Knowledge, attitudes, beliefs and behaviours of older adults about pneumococcal immunization, a Public Health Agency of Canada/Canadian Institutes of Health Research Influenza Research Network (PCIRN) investigation. BMC Public Health 2014;14:442. doi:10.1186/1471-2458-14-442.

[25] Akmatov MK, Rübsamen N, Deyneko IV, Karch A, Mikolajczyk RT. Poor knowledge of vaccination recommendations and negative attitudes towards vaccinations are independently associated with poor vaccination uptake among adults - Findings of a population-based panel study in Lower Saxony, Germany. Vaccine 2018;36:2417-26. doi:10.1016/j.vaccine.2018.03.050.

[26] Albright K, Hurley LP, Lockhart S, Gurfinkel D, Beaty B, Dickinson LM, et al. Attitudes about adult vaccines and reminder/recall in a safety net population. Vaccine 2017;35:7292-6. doi:10.1016/j.vaccine.2017.11.001.

[27] Tinsley A, Navabi S, Williams ED, Liu G, Kong L, Coates MD, et al. Increased Risk of Influenza and Influenza-Related Complications Among 140,480 Patients With Inflammatory Bowel Disease. Inflamm Bowel Dis 2018. doi:10.1093/ibd/izy243.

[28] Blumentals WA, Arreglado A, Napalkov P, Toovey S. Rheumatoid arthritis and the incidence of influenza and influenza-related complications: a retrospective cohort study. BMC Musculoskelet Disord 2012;13:158. doi:10.1186/1471-2474-13-158.

[29] Nichol KL, Nordin JD, Nelson DB, Mullooly JP, Hak E. Effectiveness of influenza vaccine in the community-dwelling elderly. N Engl J Med 2007;357:1373-81. 
doi:10.1056/NEJMoa070844.

[30] Jansen AGSC, Sanders EAM, Nichol KL, van Loon AM, Hoes AW, Hak E. Decline in influenza-associated mortality among Dutch elderly following the introduction of a nationwide vaccination program. Vaccine 2008;26:5567-74. doi:10.1016/j.vaccine.2008.08.003.

[31] Bonten MJM, Huijts SM, Bolkenbaas M, Webber C, Patterson S, Gault S, et al. Polysaccharide conjugate vaccine against pneumococcal pneumonia in adults. N Engl J Med 2015;372:1114-25. doi:10.1056/NEJMoa1408544.

[32] Jacobson Vann JC, Jacobson RM, Coyne-Beasley T, Asafu-Adjei JK, Szilagyi PG. Patient reminder and recall interventions to improve immunization rates. Cochrane Database Syst Rev 2018;1:CD003941. doi:10.1002/14651858.CD003941.pub3.

[33] Briss PA, Rodewald LE, Hinman AR, Shefer AM, Strikas RA, Bernier RR, et al. Reviews of evidence regarding interventions to improve vaccination coverage in children, adolescents, and adults. The Task Force on Community Preventive Services. Am J Prev Med 2000;18:97-140. 


\section{Tables and figures}

Table 1: main characteristics of sample population

\begin{tabular}{|c|c|c|}
\hline & & $N(\%)$ \\
\hline \multirow[t]{6}{*}{ Demographics } & Total & 208 \\
\hline & Female & $108(51.9)$ \\
\hline & Age (years) & Mean $50.6( \pm 14.7)$ \\
\hline & $<40$ & $52(25)$ \\
\hline & {$[40-64]$} & $122(58.7)$ \\
\hline & $\geq 65$ & $34(16.3)$ \\
\hline \multirow[t]{10}{*}{ Diagnosis } & Chronic inflammatory joint disease & $96(46.2)$ \\
\hline & -Rheumatoid arthritis & $56(26.9)$ \\
\hline & -Spondyloarthritis & $34(16.3)$ \\
\hline & -others & $6(2.9)$ \\
\hline & Inflammatory bowel disease & $65(31.3)$ \\
\hline & -Crohn's disease & $53(25.5)$ \\
\hline & -Ulcerative colitis & $12(5.8)$ \\
\hline & Inflammatory skin disease & $47(22.6)$ \\
\hline & -psoriasis & $44(21.2)$ \\
\hline & -others & $3(1.4)$ \\
\hline \multirow[t]{4}{*}{ Current therapies } & Conventional immunosuppressant* & 56 (26.9) \\
\hline & Biological therapy & $208(100)$ \\
\hline & TNF- $\alpha$ blockers & $157(75.5)$ \\
\hline & Abatacept (anti-CTLA4) & $18(8.7)$ \\
\hline
\end{tabular}




\section{Other conditions requiring vaccination**}

For influenza alone

For both
Age $\geq 65$ years

Morbid obesity (BMI $>40 \mathrm{~kg} / \mathrm{m}^{2}$ )

Diabetes

Chronic lung disease

Chronic kidney failure

Chronic cardiac disease

Chronic liver disease
34 (16.3)

$26(12.5)$

$9(4.3)$

$8(3.8)$

$6(2.9)$

Legends: $\mathrm{BMI}=$ body mass index; $\mathrm{CD}=$ cluster of differentiation; $\mathrm{CTLA} 4$ = cytotoxic $\mathrm{T}$ lymphocyte-associated protein 4; IL = interleukin; TNF = tumor necrosis factor *Immunosuppressant among: methotrexate, leflunomide, cyclosporine, mycophenolate mofetil, azathioprine

**We listed co-morbidities recognized as risk factors for French Health Authorities in 2014, as listed in methods, in addition to immunosuppressive treatment such as biological therapy here. 
Figure 1: vaccine coverage among the 208 patients under biological therapy for autoimmune/inflammatory disorder

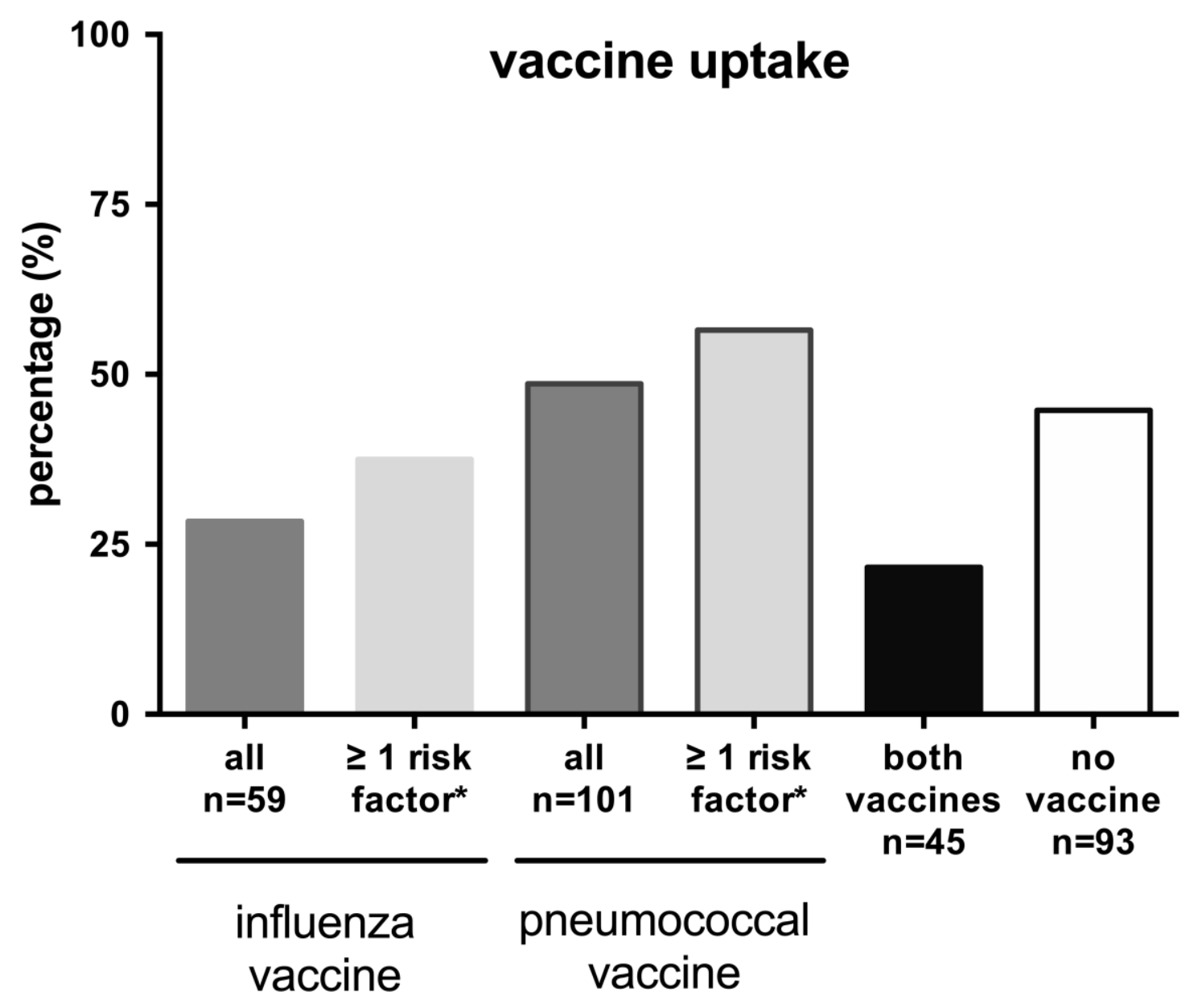

*Risk factors listed in methods, excluding the use of immunosuppressive biological therapy 
Table 2: factors associated with influenza vaccine uptake (bivariate and multivariate analysis, $N=173$ )

$\begin{array}{lllll}\text { Vaccine uptake } & \text { crude OR [95\% IC] } & \text {-value } & \text { adjusted OR [95\% IC] } & p \text {-value }\end{array}$

$$
\text { Yes, } \mathrm{N}(\%) \quad \text { No, } \mathrm{N}(\%)
$$

Total

Age class (years)

$<40$
$40-64$
$\geq 65$

Gender

-male

-female

Inflammatory disease group

-joint disease
-bowel disease
-skin disease

Received a prescription from

$50(28.9) \quad 123(71.1)$

$123(71.1)$

$\begin{array}{ccccc}5(10) & 36(29.3) & 1 \text { (ref) } & 0.02 & 1 \text { (ref) } \\ 34(68) & 72(58.5) & 3.4[1.23-9.43] & & 2.49[0.57-11.99] \\ 11(22) & 15(12.2) & 5.28[1.6-17.83) & & 4.51[0.54-37.94]\end{array}$

$\begin{array}{ccc}28(56) & 52(42.3) & 1 \text { (ref) } \\ 22(44) & 71(57.7) & 0.58[0.3-1.12]\end{array}$

0.1

1 (ref)

$0.59[0.22-1.56]$

$\begin{array}{ccccc}30(60) & 53(43.1) & 1 \text { (ref) } & 0.005 & 1 \text { (ref) } \\ 5(10) & 45(36.6) & 0.20[0.07-0.55] & & \mathbf{0 . 1 1 [ 0 . 0 2 - 0 . 6 1 ]} \\ 15(30) & 25(20.3) & 1.06[0.49-2.32] & & 1.05[0.33-3.31]\end{array}$

$1.05[0.33-3.31]$

$13(26) \quad 75(61) \quad 1$ (ref) $\quad<0.001 \quad 1$ (ref)

$<0.001$ 


-general practitioner
-specialist
-no response

Vaccine uptake in previous years

- no
-yes

Written reminder from health authority

$$
- \text { no }
$$$$
\text { -yes }
$$

Attitude toward vaccine in general

-favorable/rather favorable

-not favorable/rather not favorable

-depends on the vaccine or no opinion

Global knowledge about vaccines

$\begin{array}{ccc}19(38) & 5(4.1) & 21.92[6.96-69.08] \\ 15(30) & 21(17.1) & 4.12[1.70-10.00] \\ 3(6) & 22(17.9) & 0.79[0.21-3.01]\end{array}$

$27.48[5.23-144.43]$

$9.12[2.55-32.56]$

$0.84[0.16-4.45]$

$\begin{array}{ccc}21(42) & 104(84.6) & 1 \text { (ref) } \\ 29(58) & 19(15.4) & 7.56[3.59-4.92]\end{array}$

$<0.001$

1 (ref)

0.01

4.11 [1.37-12.38]

$\begin{array}{ccc}26(52) & 91(74) & 1 \text { (ref) } \\ 24(48) & 32(26) & 2.63[1.32-5.21]\end{array}$

0.005

1 (ref)

0.04

3.13 [1.00-9.78]

$\begin{array}{ccc}35(70) & 48(39) & 1 \text { (ref) } \\ 1(2) & 16(13) & 0.09[0.01-0.68] \\ 14(28) & 59(48) & 0.33[0.16-0.67]\end{array}$

0.001

1 (ref)

0.03

$0.04[0.003-0.46]$

0.63 [0.22-1.83]

$\begin{array}{ccc}17(34) & 60(48.8) & 1 \text { (ref) } \\ 33(66) & 63(51.2) & 1.85[0.93-3.66]\end{array}$

0.07

1 (ref)

0.03

-average/high 
Additional risk-factor for vaccination ${ }^{1,2}$

- no

-yes
$29(58)$

$21(42)$
$91(74)$

$32(26)$
1 (ref)

2.06 [1.03-4.11]

Patient received advice for vaccine uptake ${ }^{1}$

- no

-yes

$<0.001$

$49(39.8) \quad 7.93[3.43-18.33]$

Legend: for each analysis the reference (ref) group is indicated (odds ratio $=1$ ). The adjusted odds ratio are inferred from this reference group, with values above 1 corresponding to a better vaccine uptake and values below 1 corresponding to a lower uptake.

${ }^{1}$ Variables included in the multivariate model but not selected by the backward stepwise selection

${ }^{2}$ Risk-factors for which vaccination is recommended: age $\geq 65$, chronic lung disease, chronic cardiac failure, chronic kidney failure, immune deficiency, morbid obesity, diabetes, pregnancy 
Table 3: factors associated with pneumococcal vaccine uptake (bivariate and multivariate analysis, $\mathrm{N}=173$ )

\begin{tabular}{|c|c|c|c|c|c|c|}
\hline & \multicolumn{2}{|c|}{ Vaccine uptake } & \multirow[t]{2}{*}{ crude OR [95\% IC] } & \multirow[t]{2}{*}{$p$-value } & \multirow[t]{2}{*}{ adjusted OR $[95 \%$ IC $]$} & \multirow[t]{2}{*}{$p$-value } \\
\hline & Yes, N (\%) & No, N (\%) & & & & \\
\hline Total & $90(53.2)$ & $83(46.8)$ & & & & \\
\hline \multicolumn{7}{|l|}{ Age class (years) } \\
\hline$<40$ & $19(21.1)$ & $22(26.5)$ & 1 (ref) & 0.7 & 1 (ref) & 0.8 \\
\hline $40-64$ & $57(63.3)$ & $49(59)$ & $1.35[0.65-2.78]$ & & $1.04[0.43-2.50]$ & \\
\hline$\geq 65$ & $14(15.6)$ & $12(14.5)$ & $1.35[0.50-3.62]$ & & $1.39[0.42-4.67]$ & \\
\hline \multicolumn{7}{|l|}{ Gender } \\
\hline -male & $39(43.3)$ & $41(49.4)$ & 1 (ref) & 0.4 & 1 (ref) & 0.6 \\
\hline -female & $51(56.7)$ & $42(50.6)$ & $1.28[0.70-2.32]$ & & $1.19[0.61-2.31]$ & \\
\hline \multicolumn{7}{|c|}{ Inflammatory disease group } \\
\hline -joint disease & $52(57.8)$ & $31(37.3)$ & 1 (ref) & 0.01 & 1 (ref) & 0.03 \\
\hline -bowel disease & $18(20)$ & $32(38.6)$ & $0.34[0.16-0.70]$ & & $0.33[0.14-0.77]$ & \\
\hline -skin disease & $20(22.2)$ & $20(24.1)$ & $0.60[0.28-1.28]$ & & $0.68[0.30-1.53]$ & \\
\hline
\end{tabular}


-nobody

-general practitioner

-specialist

-no response

Global knowledge about vaccines

\section{-restricted/low}

-average/high

Conventional IS associated ${ }^{1}$ -no

-yes
$13(14.4)$

$9(10)$

30 (33.3)

$38(42.2)$

$34(37.8)$

$56(62.2)$

$61(67.8)$

$29(32.2)$
0.01

1 (ref)

$4.14[0.96-17.87]$

$3.80[1.38-10.45]$

$1.33[0.56-3.16]$
0.01

$3.46[0.88-13.61]$

3.85 [1.46-10.12]

$1.24[0.55-2.82]$
$64(77.1)$

$19(22.9)$

0.07

$40(48.2) \quad 1.77[0.97-3.24]$

1 (ref)

0.1

$1.60[0,81-3.15]$

Patient received advice for vaccine uptake ${ }^{1}$

- no

-yes
48 (53.3)

42 (46.7)
$61(73.5)$

22 (25.5)
1 (ref)

2.43 [1.28-4.60]

Legend: for each analysis the reference (ref) group is indicated (odds ratio $=1$ ). The adjusted odds ratios are inferred from this reference group, with values above 1 corresponding to a better vaccine uptake and values below 1 corresponding to a lower uptake. IS =immunosuppressant

${ }^{1}$ Variables included in the multivariate model but not selected by the backward stepwise selection 